\title{
Aspectos psicossociais da homofobia intrafamiliar e saúde de jovens lésbicas e gays
}

\author{
Juliana Perucchi \\ Brune Coelho Brandão \\ Hortênsia Isabela dos Santos Vieira \\ Universidade Federal de Juiz de Fora
}

\begin{abstract}
Resumo
O número de pesquisas sobre diferentes aspectos da homofobia cresceu nos últimos dez anos. Entretanto, há uma carência de estudos que analisem os aspectos psicossociais que envolvem as experiências de jovens lésbicas e gays mediante situações de violência e os desdobramentos destas na sua saúde. O presente artigo busca relatar os resultados de uma pesquisa que objetivou analisar como se constituem as situações de homofobia no âmbito das relações familiares vividas por jovens lésbicas e gays, analisando os aspectos psicossociais dos processos de ruptura ou afastamento temporário ou permanente do vínculo familiar. A hipótese confirmada ao longo desses anos de pesquisa é de que o preconceito se articula no contexto familiar como dispositivo de legitimação da violência e, consequentemente, ocasiona a ruptura do vínculo, o afastamento temporário ou permanente entre jovens lésbicas e gays e seus familiares, levando, muitas vezes, à saída ou à expulsão da casa dos pais em circunstâncias complexas e, frequentemente, dolorosas.
\end{abstract}

Palavras-chave: Juventude LGBT; homofobia; família; saúde; violência.

\begin{abstract}
Psychosocial aspects of homophobia in families and health of young lesbian and gay. The number of studies on different aspects of homophobia has grown significantly in the last ten years. However there is a lack of studies that analyze the psychosocial aspects involving experiences of LGBT youth by situations of violence and its consequences on their health. The present article reports the results of a research that aimed to analyses as are the situations of homophobia in the context of family relationships experienced by lesbian and gay youth, examining the psychosocial aspects of them processes of rupture or temporary or permanent familiar bond. The hypothesis confirmed during these years of research is that prejudice is articulated in the family context as a device to legitimize the violence and consequently causes the rupture of the bond, temporary or permanent among lesbian and gay youth and their families, which leads often leading to or expulsion from the house of the parents in complex circumstances and often painful.
\end{abstract}

Keywords: LGBT youth; homophobia; family; health; violence.

\section{Resumen}

Aspectos psicosociales de la homofobia intrafamiliar y la salud de los jóvenes lesbianas y gays. El número de estudios sobre diferentes aspectos de la homofobia ha crecido en los últimos diez años. Sin embargo, hay una falta de estudios que analizan los aspectos psicosociales relacionados con las experiencias de violencia de jóvenes LGBT y las consecuencias de éstas en su salud. Este artículo tiene como objetivo informar de los resultados de una investigación con el objetivo de analizar como son los casos de homofobia en el contexto de las relaciones familiares que experimentan los jóvenes lesbianas y gays, examinando los aspectos psicosociales de los procesos de ruptura o remoción momentánea o permanente con su familia. La hipótesis confirmada durante estos años de investigación es que el prejuicio se articula en el contexto familiar como un dispositivo para legitimar la violencia y, en consecuencia, provoca la ruptura del vínculo, la remoción momentánea o permanente de los jóvenes lesbianas y gays fuera de sus familias, y muchas veces, la salida o expulsión de la casa de sus padres son en circunstancias complejas, a menudo dolorosas.

Palabras clave: jóvenes LGBT; homofobia; familia; salud; violencia. 
E ste artigo analisa como se constituem as situações de homofobia no âmbito das relações familiares vividas por jovens lésbicas e gays, analisando os aspectos psicossociais dos processos de ruptura ou afastamento temporário ou permanente do vínculo familiar por parte de jovens lésbicas e gays. A hipótese confirmada ao longo desses anos de pesquisa é de que o preconceito se articula no contexto familiar como dispositivo de legitimação da violência e, consequentemente, ocasiona a ruptura do vínculo, o afastamento temporário ou permanente entre jovens lésbicas e gays e seus familiares, o que leva, muitas vezes, à saída ou à expulsão da casa dos pais em circunstâncias complexas e, frequentemente, dolorosas.

A homofobia pode ser caracterizada como uma atitude hostil a homossexuais, de modo a designar o outro como inferior, anormal, desviante (Borrillo, 2001). Em seu cerne, encontra-se, segundo Rubin (1984), a hierarquia das sexualidades que, baseada na heteronormatividade, confere à heterossexualidade um status superior e à homossexualidade um lugar marginal. Sendo assim, heteronormatividade ou norma heterossexual refere-se a uma racionalidade que contempla normas, valores, princípios de conduta e dispositivos, por meio da qual a heterossexualidade é instituída como a única possibilidade legítima e natural de expressão identitária e sexual (Warner, 1993). É por meio desse mecanismo cotidiano de exclusão de quaisquer outras possibilidades de experiência da sexualidade que a homofobia atua como um mecanismo de proteção das fronteiras sexuais e das fronteiras de gênero (Blumenfeld, 1992) e pode ser utilizada como um dispositivo que (re)produz um sistema de diferenças que legitima e justifica a exclusão e dominação de determinados sujeitos. Como afirma Gayle Rubin (1984, p. 279) "atos sexuais são sobrecarregados com um excesso de significado”.

A homofobia se aproxima de outras formas de discriminação como a xenofobia, o racismo e o antissemitismo, pois consiste em considerar o outro (no caso o/a homossexual e transgêneros) como desigual, inferior, anormal. Além disso, como qualquer outra forma de intolerância, a homofobia se articula em torno de emoções, condutas e dispositivos ideológicos e institucionais, configurando-se como um instrumento que cria e reproduz um sistema de diferenças para justificar a exclusão e a dominação de uns sobre outros.

Portanto, um importante aspecto a ser enfatizado para se compreender a homofobia é que a complexidade e diversidade das práticas discriminatórias por conta da orientação sexual se articulam com outros marcadores sociais como raça/etnia, classe, geração, gênero. Dessa maneira, a homofobia, apesar de ser uma discriminação comum a gays, lésbicas, bissexuais, travestis e transexuais, atinge diferentemente cada um destes sujeitos segundo as diferentes categorias sociais que constituem a produção de suas subjetividades e que marcam a localização dos mesmos nas hierarquias sociais (Marsiaj, 2003).

Uma nuance da homofobia investigada na literatura e que encontra nos estudos da psicologia um campo de saber fértil é a que se refere à "homofobia internalizada" que "consiste na canalização para o self do próprio homossexual de todas as atitudes de valor negativas, levando a desvalorização desse self, resultando em conflitos internos e pouca auto-estima" (Pereira \& Leal, 2005, p. 323). Dessa maneira, Pereira e Leal (2005), pressupõem que ao assumir a homossexualidade (coming out) a homofobia internalizada tende a diminuir, ocorrendo um "ajustamento" saudável do sujeito. Esta análise da homofobia, ao focar no indivíduo e numa visão psicologizante do fenômeno, acaba por negligenciar mecanismos sociais, relacionais e intersubjetivos da construção da homofobia como um sistema de opressão que abrange âmbitos intraindividual, individual, interacional, institucional e social (Pelegrinni, 1992). Dessa maneira, as pesquisas psicológicas que têm estudado a homofobia internalizada parecem ser ainda limitadas para a análise da homofobia como um sistema interestruturado de opressão que busca a manutenção de hierarquias sociais e de controle de alguns sobre outros.

A presente pesquisa considera a homofobia como um fenômeno complexo e multifacetado, com dimensões psicológicas e sociais que se processam na experiência individual dos sujeitos, mas que não se encerram na individualidade, processando-se no âmbito das relações sociais. Nesse sentido, romper com o modelo de homofobia assimilada é uma forma de superar a ideia de que há um conjunto de valores considerados corretos, valores estes que impossibilitam que a vivência homossexual seja considerada uma vivência legítima. Ao, então, assumir a legitimidade das experiências homoeróticas, há um reposicionamento na própria história individual e coletiva desses sujeitos, visto que os valores morais são constituidores das identidades e das culturas. A homofobia impossibilita, sob a óptica social, que os indivíduos possam se assumir homossexuais de uma forma mais legítima e que não se consolidem em uma identidade menos subordinada, bem como legitima expressões, muitas vezes violentas, de ódio e preconceito (Prado \& Machado, 2008).

Investigações em contextos socioculturais internacionais (Allen, Glicken, Beach, \& Naylor, 1998; Lancaster, 1999) têm mostrado que os desejos e práticas homossexuais, assim como a homofobia, não são fenômenos que se processam apenas com pessoas adultas. Contudo, há uma carência de pesquisas sobre homofobia intrafamiliar e, neste sentido, constata-se que: "esse locus de manifestação da homofobia, obscurecido pela intimidade do mundo privado, é ainda uma seara pouco discutida nos estudos nacionais e potencializa os danos causados pela discriminação nos espaços macrossociais" (Toledo \& Teixeira Filho, 2013, p. 376). Pesquisas internacionais têm constatado elementos homofóbicos relacionados ao bullying e à violência nas escolas, incluindo aspectos da cultura institucional e dos conteúdos que se articulam aos comportamentos agressivos entre estudantes (Kimmel \& Mahler, 2003; Poteat \& Espelage, 2007). Conteúdo homofóbico tem sido um elemento identificado como associado à agressão por pares nas escolas. Algumas pesquisas realizadas entre estudantes gays e lésbicas e da população estudantil em geral (majoritariamente 
heterossexual) indica que o uso do conteúdo verbal homofóbico é algo que se destaca na homofobia que se expressa e se promulga entre os estudantes por meio de várias formas de agressão que incluem temas e referências preconceituosas e discriminatórias (Kosciw, 2004; Phoenix, Frosh, \& Pattman, 2003; Pilkington \& D’Augelli, 1995; Plummer, 2001; Poteat \& Espelage, 2007; Rivers, 2001).

Frequentemente, a iniciação da vida sexual ocorre no período da adolescência ou no início da juventude e se configura como um contexto de experiências importantes para o processo de constituição do sujeito, não apenas no âmbito da sua sexualidade, mas também no que se refere a outras dimensões importantes da vida, como a busca de autonomia, o senso de responsabilidade e a gradativa independência afetiva da família de origem. Entretanto, considerando as diversas nuances que a homofobia possui e que atravessam a sociedade, sobretudo, nos níveis institucionais, a vivência da sexualidade pelos adolescentes e jovens fora dos parâmetros da norma heterossexual passa a ser para muitos(as) deles(as) o estopim de uma série de violências legitimadas pelo preconceito. Situações de violência perpetradas, inclusive, no contexto familiar. Além disso, Rios e Nascimento (2007) destacam que são pouco expressivas as análises acerca do descompasso entre o marco legal sobre o direito de crianças e adolescentes (Lei n. ${ }^{\circ}$ 8.069) e a atuação de diferentes atores sociais responsáveis por zelar pelo bem estar e desenvolvimento destas no que se refere à vivência da homossexualidade (Abramovay, Castro, \& Silva, 2004; Souza, 2006; SPDCA/SEDH/PR, 2004).

Sendo assim, a família, instituição por meio da qual valores e crenças são perpetuados em relações carregadas de emoções, se configura como espaço no qual as regularidades objetivas da vida cotidiana passam a ser incorporadas espontaneamente por seus membros. Portanto, ela não está isenta ao funcionamento da heteronormatividade, atuando, ao contrário, como um eficiente dispositivo de reprodução e reiteração da norma e da repetição das formas de discriminação e violência que podem ser visualizadas em contextos mais amplos da sociedade em geral. Assim, a família opera no micro contexto das relações de parentesco e coabitação, reproduzindo modelos hierárquicos e opressores. Os laços familiares, de uma forma ou de outra, continuam ocupando lugar de destaque na construção da maneira com que a maioria das pessoas vê e vive o mundo; portanto, analisar o contexto da família como espaço no qual a violência pode estar sendo legitimada pela ótica do preconceito e da homofobia é entender a família como instituição por meio da qual um conjunto de valores é transmitido, permitindo aos indivíduos a construção de sua identidade e atribuindo à vida de seus membros um sentido (Osório, 1996).

\section{Método}

O método de trabalho de campo, inspirado na etnografia (Fonseca, 1999), leva em consideração as diferenças entre os(as) entrevistados(as). Não encarando o universo de pesquisa como um todo homogêneo, percebendo a particularidade dos diferentes casos e procurando contemplar tais particularidades na análise. Tentou-se escapar do que Claudia Fonseca (1999) denominou de "individualismo metodológico", por meio do qual instaura uma forte tendência a isolar o indivíduo de seu grupo social, fazendo com que a "pesquisa de campo" se reduza a entrevistas quase terapêticas entre apenas duas pessoas. Assim, a equipe de pesquisa fez importantes imersões aos contextos de sociabilidade de jovens LGBT de classes populares de um município de médio porte, já que a abordagem etnográfica de produção científica exige uma atenção especial às diferentes linguagens cotidianas que técnicas de entrevista têm mais dificuldade em alcançar (Fonseca, 1999).

A metodologia utilizada contemplou, portanto, um enfoque qualitativo, tendo como procedimento de coleta de informações, observação participante e entrevistas semi-estruturadas, com informantes de uma amostra de conveniência, constituída por saturação (Marre, 1991). Os critérios de inclusão da amostra foram: possuir algum tipo de conflito familiar em decorrência da sua orientação sexual e/ou identidade de gênero; habitar na cidade de abrangência do estudo; possuir entre 18 e 30 anos, de ambos os gêneros; e que já haviam vivenciado algum tipo de experiência homoerótica. Participaram da pesquisa 10 jovens, sendo cinco homens e cinco mulheres (não houve participação de pessoas transexuais ou travestis, o que limita a envergadura da compreensão da problemática no que se refere a essa população). As pessoas participantes da pesquisa tinham idade entre 19 e 23 anos e residiam em bairros de camadas populares.

$\mathrm{O}$ acesso às/aosjovens se deu por meio de indicações de pessoas (informantes-chave) que circulam por espaços de sociabilidade LGBT no contexto investigado e, por meio delas, acionou-se a rede social dessas pessoas, permitindo o acesso a outras pessoas que se enquadrassem nos critérios de participação na pesquisa: que se reconheçam como LGBT, que tenham entre 18 e 30 anos, que tenham vivenciado ou que estejam vivenciando situações de violência familiar decorrente de sua orientação sexual. De modo geral, como afirmam Débora Diniz e Iara Guerriero (2008), os informantes-chaves, são aquelas pessoas que no desenvolvimento do trabalho de campo garantirão a entrada na sociedade ou no grupo a ser estudado, assegurando a entrada do pesquisador no campo e protegendo-o das suspeitas da comunidade. Os/as informantes foram contatados individualmente por telefone, ocasião em que foram convidados/as a participar da pesquisa. Uma vez aceito o convite, assinavam o termo de Consentimento Livre e Esclarecido, por meio do qual os/as participantes foram informados(as) dos aspectos éticos e metodológicos que envolviam a pesquisa. A data, o horário e o local das entrevistas foram marcados conforme disponibilidade do(a) informante. O roteiro de entrevista tinha como principais analisadores: orientação sexual, identidade de gênero, conflito familiar decorrente da orientação sexual e/ou identidade de gênero, expulsão/ saída de casa, discriminação, violência, impacto dos conflitos 
na saúde física e mental, estratégias de enfrentamento frente ao conflito, redes de apoio e "saída do armário".

Todas as entrevistas foram gravadas e transcritas integralmente. O material resultante das entrevistas foi organizado por meio de arquivo e analisado pelo procedimento de descrição dos enunciados - acontecimentos do discurso (Foucault, 2004a, p. 30) - que aparecem nas formações discursivas materializadas nas narrativas orais dos(as) informantes da pesquisa; estabelecendo suas correlações com outros enunciados aos quais pode estar ligado ou, como afirma Foucault (2004a, p. 31), "mostrar que outras formas de enunciação exclui".

Assim, a abordagem teórico-metodológica adotada possibilitou que aspectos da vida social dos sujeitos que compõem enunciados fossem descritos e examinados a partir da ótica da produção de sentidos, que, longe de serem concebidos como naturais e aparentemente imutáveis ou oriundos de discursos previamente arranjados, possam então ser alvo de problematização e de análise. Por conseguinte, orientando-se pela perspectiva teórico-metodológica da análise do discurso, de Michel Foucault, este relato considera que tais aspectos da vida dos sujeitos participantes da pesquisa constituem uma objetividade: a formação de uma política e de um governo de si, a elaboração de uma ética e de uma estética de si mesmo. Assim, na análise das entrevistas, privilegiou-se constatar o lugar ocupado pelos jogos de verdade, pelas relações de poder e, sobretudo, pelas formas de relação do sujeito consigo e com os outros, na construção de um campo de experiências das sexualidades de jovens gays e lésbicas. Neste sentido, compartilha-se da perspectiva de que:

No intercâmbio sério de perguntas e respostas, no trabalho de elucidação recíproca, os direitos de cada pessoa são de algum modo imanentes a discussão. Derivam da situação de diálogo. (...) Quem pergunta limita-se a exercer um direito seu: o de não estar convencido, de colher uma contradição, ter necessidade de informação ulterior, fazer valer postulados diversos, sublinhar um defeito na argumentação. Quanto a quem responde, nem sequer ele tem um direito que excede à própria discussão; está ligado, pela lógica do seu discurso ao que disse antes e, pela aceitação do diálogo, à pergunta do outro. Perguntas e respostas dependem de um jogo, um jogo que é ao mesmo tempo prazeroso e difícil, no qual cada um dos dois parceiros se compromete a só usar os direitos que lhe são dados pelo outro e pela aceitação da forma de diálogo $\mathrm{O}$ polemista procede baseado nos privilégios que tem de antemão e nunca vai questionar. (...) O polemista assume uma legitimidade que por definição é negada a seu adversário (Rabinow, 1999, p.17-18).

Sendo assim, este texto procura escapar à polêmica que acompanha o tema das homossexualidades juvenis. Pois, como afirma Michel Foucault, o polemista não está disposto a ouvir, mas apenas a enunciar "a verdade na forma de julgamento e de acordo com a autoridade que ele próprio se atribuiu" e isso pouco interessa (Foucault, 2004b, p. 226). O que se busca aqui, sobretudo, no que concerne ao tema deste artigo, é a problematização das homossexualidades juvenis e das violências intrafamiliares perpetradas a jovens gays e lésbicas. Dito de outro modo, a escrita deste relato de pesquisa orientou-se pela atitude metodológica que entende tais "objetos de estudo" como produtos de relações de força forjados nas lutas entre discursos de verdade. Sendo assim, o sentido das situações de violência homofóbica - e outras a elas correlacionadas - vividas pelos/as jovens participantes da pesquisa, materializado em enunciados de narrativas orais, constituem-se material privilegiado para análise.

A análise que se segue neste relato orientada pelo método de análise do discurso, de enfoque foucaultiano, está ancorada teoricamente nas teorias críticas em psicologia social, nas teorias queer e nos estudos feministas. Tal desenho teórico-metodológico parte da premissa que são nas vivências cotidianas de jovens gays e lésbicas que poderemos encontrar as fontes de informação para nossas reflexões analíticas. Neste contexto, os relatos dos próprios atores sociais sobre a problemática investigada configuram-se como material discursivo no qual se revelam os sentidos atribuídos aos acontecimentos da existência (Sahlins, 1990).

\section{Resultados e discussão}

Devido à rejeição e à discriminação existente no meio social, nas escolas, nas famílias, enfim, nas instituições sociais, torna-se difícil para um(a) adolescente assumir-se como não -heterossexual, e quando o faz perante a família, dificilmente encontra acolhimento e respeito (Remafedi, 1987). Corroborando com tal hipótese, a partir do material discursivo produzido no trabalho de pesquisa, constatou-se que o início do conflito familiar ocorre com a "saída do armário", ou seja, com a revelação da orientação do desejo voltada para alguém do mesmo sexo. Tal revelação, entretanto, pode acontecer intencionalmente ou à revelia da vontade das pessoas e, neste sentido, Eve Sedgwick (2007) aponta o armário como um dispositivo de regulação da vida de gays e lésbicas, mas também, de heterossexuais e seus privilégios de visibilidade e hegemonia de valores. Neste sentido a fala da informante corrobora com as informações da literatura acerca de um estopim de conflitos a partir da saída do armário.

(...) não dá para esconder, não dá para ficar de baixo dos panos mais, por mais que não aceite, seja lá qual for a reação eles precisam saber, e aí eu resolvi contar, aí contei para minha mãe, ela passou uma semana me ignorando, aí e querendo que eu contasse para o meu pai e eu disse que não ia contar, aí ficou meio que isso, aí no final de semana ela já tinha contado para ele e eles me chamaram para conversar, aí foi horrivel. (Amanda, 23 anos).

Nesta perspectiva, a autora aponta que o armário representa algo que marca a vida de gays e lésbicas. A cada encontro com uma nova pessoa, novos armários são construídos, os quais demandam novos esquemas e demandas de sigilo ou exposição. Assim, mesmo pessoas que se assumem homossexuais, são poucas as que não se encontram no armário com alguém que seja de alguma forma importante para elas. Este fato pode ser ilustrado com a fala de uma das entrevistadas ao ser indagado a ela a respeito de estar ou não dentro do armário:

Ah é complicado, né? Meio a meio, né? Porque me assumi, e assumi para os meus pais, então já é metade do caminho. Mas para o resto da população teoricamente eu não me assumi, eu acho que assim, a maioria das pessoas que convivem comigo, acho que acabam sabendo 
de uma forma ou de outra, até porque minha namorada está sempre comigo, a gente trabalha no mesmo local. Então é difícil, mas eu não assumo, digamos assim, eu não conto, então partes, a outra metade está dentro do armário. (Amanda, 23 anos)

Deve-se ter em conta que a dinâmica da (in)visibilidade, sobretudo, no que se refere às identidades não heterossexuais, precisa ser compreendida no âmbito do próprio funcionamento das configurações geopolíticas das democracias contemporâneas e das sociedades liberais e seus sistemas econômicos. Assim, falar ou não falar, assumir ou não uma identidade, não deve ser analisado como fenômeno isolado ou imune à lógica da confissão moderna; confissão esta que já não tem como alvo a renúncia de si, para o desespero de alguns fundamentalistas religiosos. Confessa-se hoje com o intuito de afirmar, de revelar identidades e tais revelações têm função importante na docilização dos corpos. Tais enunciações confessionais de si constituem um poderoso dispositivo de repetição das performances da obediência moderna dos corpos desejantes (Butler, 2006; Preciado, 2011). De tal modo, tais dispositivos de poder produzem subjetividades suficientemente dóceis e facilmente identificáveis, exigência da própria ordem social hegemônica. Portanto, nossas constatações vão ao sentido de corroborar outros estudos (Saggese, 2009) que apontam que, quando um gay ou uma lésbica está diante de uma situação em que é possível sair do armário, ele(a) pode ser tomado(a) por um sentimento ambivalente de dúvida frente à certeza da revelação. Tais contextos comunicacionais constituem um campo de experiências central na vida dos jovens gays e lésbicas, pois os/as inscreve na arena pública e isso tem implicações.

Cheguei num ponto que eu não tinha para onde fugir entendeu? É assim, o armário já tava ficando pequeno pra mim, lá dentro entendeu? Então assim, eu precisava ter essa postura (...) Já fui direto ao meu pai, então assim, era quem precisava saber naquele momento. O que ele vai fazer com a informação depois, se ele vai digerir, se ele vai espalhar ela, como ele fez, o problema é dele, mas eu falei. (Ruan, 25 anos)

No que concerne às relações familiares, ainda que, no senso comum, se considere que o espaço familiar seja de agregação de indivíduos, há nesta agregação a exigência de que a postura de seus membros seja compatível ao modelo hegemônico - tanto na organização e estruturação da família, enquanto instituição social, quanto às condutas de seus membros. Sendo assim, se seus membros são considerados como desviantes a tais regras, a família passa a se dispor de mecanismos violentos, sejam estes físicos ou psicológicos, na tentativa de repreendê-los e enquadrá-los à norma (Soliva, 2009). Assim, quando há o comming out, ou seja, a revelação da orientação sexual considerada desviante, de um sujeito dentro do seu próprio seio familiar, percebe-se que a família não atua como protetora e promotora de saúde e dignidade de tais indivíduos, mas, pelo contrário, como um dispositivo de reiteração da heteronorma através de formas de violência pautadas na inferiorização das experiências desviantes.

Os trechos seguintes destacam como a revelação da orientação sexual desses/as jovens impactou negativamente as relações familiares, sendo então o ponto de partida para uma série de conflitos que culminam em situação de violência.

Antes da fatídica notícia era bom, era normal, relacionamento normal, até que eu resolvi contar, que sou lésbica, aí as coisas já mudaram bastante de figura, eu contei a principio só para minha mãe, ela ficou bastante decepcionada, bastante chateada, mas ficou quietinha, quietinha entre aspas né... ficou uma semana inteira me ignorando, nem olhava na minha cara. (Amanda, 23 anos)

Olha, antes de acontecer todo o processo de eu me assumir e tudo mais, era um pouco mais tranquilo. Tinha uma convivência melhor, dava pra conversar um pouco. Tá que não foi uma família de (...) diálogo, grande diálogo (...) porque aí depois que aconteceu, que eu me assumi (...) mais começou as brigas mais frequentes, desentendimentos". (Igor, 22 anos)

Ah, hoje a gente está vivendo um conflito né (...) porque meus pais ficaram sabendo que eu tenho uma namorada. (...) Mas a minha mãe e eu, a gente acaba brigando muito por causa disso, o meu irmão parou de conversar comigo". (Fabiane, 28 anos)

Desta forma, foi possível perceber também que a família não funciona como uma rede de apoio significativa para esses(as) jovens que, na maioria das vezes, conta apenas com amigos e/ou amigas para dividir as suas experiências e dificuldades. Vale destacar que a rede de apoio social é definida por Sluzki (1997, p. 15) como:

(...) conjunto de seres com que interagimos de maneira regular, com quem conversamos, com quem trocamos sinais que nos corporizam, que nos tornam reais. De fato, esta experiência coerente no tempo e no espaço, que constitui a nossa identidade se constrói e reconstrói constantemente no curso de nossas vidas com base em nossa interação com os outros.

Essas redes envolvem todas as relações do indivíduo, como as relações comunitárias, em família, no trabalho, na escola e as amizades. Estas podem tanto favorecer a promoção do bem -estar, desenvolvimento da identidade, como também desencadear um processo de mal estar e adoecimento (Sluzki, 1997). A família, portanto, que poderia se constituir como promotora do bem-estar, antagonicamente colaborou para o desencadeamento de situações constrangedoras e dolorosas para esses(as) jovens que buscaram apoio em suas redes de amizades, as quais ainda assim se mostraram frágeis e escassas. Assim, o espaço familiar, que deveria ser acolhedor, inserindo o jovem na dinâmica da sociedade e ofertar segurança, torna-se um ambiente hostil buscando reenquadrar o sujeito, através de mecanismos violentos, a parâmetros binários e naturalizados de exercício da sexualidade. Para ilustrar, segue um fragmento de narrativa de um jovem participante da pesquisa:

Ela (a mãe) parou de falar comigo totalmente. Eu chegava perto dela ela afastava, ela não ficava perto, vivia brigando comigo, chorando, escandalizando. Tipo, eu perguntava: "que foi mãe?" e ela dizia: "nada não”. Ai, uma hora ela me chamou para ir ao quarto, fechou a porta e conversou comigo. Isso foi num sábado, que ela conversou comigo, e eu fui embora de casa no sábado mesmo, porque ela me expulsou. Ela teve essa conversa comigo e falou "vai embora agora e não volta mais pra casa. Fica longe para sempre”. Foi terrível. A partir daí, tudo desandou com a minha mãe. Ela não falava comigo direito, falava só o que era necessário, finanças, fazia de tudo para eu não ir para casa, e quando eu não ia, inventava desculpa para o meu pai, de porque que eu tinha que ficar na cidade em tal feriado, no final de semana que era para eu ir para lá. (Júlio, 20 anos) 
No caso de Júlio, a violência homofóbica culminou em uma expulsão da casa de seus pais, além da rejeição por parte de sua mãe que criava estratégias para que o filho não aparecesse em sua cidade natal. Isto porque se tratava de uma cidade pequena e a mãe tinha medo de que o "segredo" do filho pudesse ser revelado. Sendo assim, na compreensão que Júlio faz dessa experiência, a repercussão da sua identidade homossexual, ao ser explicitada no espaço público da cidade, afetaria negativamente a rede social de sua família, rede esta cujo funcionamento é constituído por jogos de poder e por privilégios mantidos entre as famílias heterossexuais. Não é de estranhar que o armário tenha se estabelecido para este jovem como única saída possível, na dinâmica das relações que ele estabeleceu em sua cidade natal. O armário efetivou-se sobremaneira, uma vez que a mãe, ocupando um lugar de "correção", procurou evitar que a revelação do "desvio de conduta" de seu filho escapasse do domínio da vida privada de seu lar ao domínio da vida pública, explicitando a incapacidade da família em garantir - muitas vezes, violentamente - que seus membros se mantenham nas fronteiras de gênero e da heteronorma. Neste aspecto, vê-se operando o que pode ser definido pelo conceito de violência, tal como definido por Maria Cecília de Souza Minayo:

Aquela que oferece um marco à violência do comportamento e se aplica tanto às estruturas organizadas e institucionalizadas da família como aos sistemas econômicos, culturais e políticos que conduzem à opressão de grupos, classes, nações e indivíduos, aos quais são negadas conquistas da sociedade, tornando-os mais vulneráveis que outros ao sofrimento e à morte (Minayo, 1994, p. 8).

A autora afirma que estas estruturas operam nas práticas de socialização, levando o indivíduo a aceitar sofrimentos de uma forma naturalizada. Embora a maioria dos(as) jovens participantes da pesquisa tenha afirmado sofrer discriminação pelos seus familiares devido à sua sexualidade, percebe-se que alguns(mas) desses(as) jovens, contudo, não reconhecem algumas situações às quais passam, como situações discriminatórias e de violência. Isso fica mais explícito nos casos de violência simbólica, que ocorre através do tratamento diferenciado, das piadas e dos deboches em reuniões familiares.

Eu não sei se chega a ser discriminação [pausa], é meio difícil dizer assim, porque é preconceito, de uma forma ou de outra é preconceito, mas como é com meu pai e com a minha mãe é muito difícil de você entender isso como preconceito também, eles ficam arredios mas em momento nenhum xingaram ou falaram nada desagradável assim, só ficaram muito chateados, eles não entendiam porque, achavam que eles tinham errado em alguma coisa. (Amanda, 23 anos)

A questão da visibilidade mostra-se como um divisor de águas na vida desses(as) jovens, os quais passam a ser tratados de modo distinto em sua família e têm suas histórias de vida marcadas por episódios violentos, sujeitos ao desprezo e à marginalização por parte de seus familiares. Neste sentido, a pesquisa corrobora com estudos internacionais que constatam que as construções cotidianas de identidade de gênero geradas dentro da ordem social dominante produzem violência anti-homossexual (Tomsen, 2001; 2002; 2006), tendo como impactos, práticas coercitivas, corretivas e punitivas, opera- das por meio da violação de direitos e/ou de crimes, velados ou explícitos, ou simplesmente, por violências cotidianas.

Porque como eu falei não houve xingamento, nada desse tipo, mas o fato de ela ter se afastado, ter se recolhido, ter parado de falar durante uma semana comigo, não me olhava no rosto e tal, foi muito doloroso, porque lá em casa a gente conversa muito, a gente não é muito de abraço, beijo, muito de carinho assim, de contato, a gente conversa muito, e ela ter parado de conversar comigo foi uma prova de que ela não aceitou, então foi bem difícil, essa primeira semana [após a saída do armário] principalmente foi terrível. (Amanda, 23 anos)

Eh, no caso (...) estávamos discutindo [ele e a mãe, referente a sua orientação sexual]. Num sei o quê que eu falei, ele [o irmão mais novo] veio, avançou em mim, me empurrou contra... ele tava na copa e tinha uma mesa, me empurrou contra a mesa. Não entendi, fiquei sem reação, e começou a me bater. Não me lembro o porquê que ele começou. (Igor, 22 anos)

A análise dos relatos orais permite constatar que situações de homofobia no contexto familiar se constituem a partir de dispositivos com efeitos psicossociais no curso de vida dos/ as jovens: mecanismos subjetivos que mantêm o silêncio e a impotência diante da violência não apenas física, mas, sobretudo, simbólica, por meio dos quais a norma heterossexual submete jovens gays e lésbicas a estratégias biopolíticas de controle dos seus corpos. Por meio da análise das entrevistas, percebe-se que a família, quando não toma uma postura violenta na tentativa de reprimir a expressão das vivências homoeróticas dos(as) jovens, muitas vezes se utiliza de uma forma de silêncio, de invisibilidade das práticas. Mais que isso, a questão de "fingir não ver" mostra-se como uma maneira que os pais e os familiares se utilizam para evitar o tema, na tentativa que as práticas desviantes fossem de algum modo caladas ou, ao menos, contidas. Como nos excertos abaixo:

E o meu pai é muito tranquilo ele não fala sobre o assunto, é como se não existisse. (Joana, 27 anos).

Meu pai é como se nada tivesse acontecido depois de um certo tempo assim, há uns dois meses ele ficou mais arredio e tal, agora ele me trata como se nada tivesse acontecido, como se ele não soubesse de nada, como se não houvesse nada para saber, finge que não existe, para levar tudo numa boa (...). Foi meio que ignorar os fatos, eles para conseguir lidar com a situação e a gente voltar digamos assim, ao normal, eles ignoraram, era como se eles não soubessem de nada. Então não tinha porque haver conflito, já que o assunto não era falado, a gente não tratava sobre ele então, não tinha como acontecer o conflito. (Amanda, 23 anos)

A pesquisa constatou ainda outros resultados pertinentes da análise. Uma constatação foi de que a expulsão da casa dos pais não é a expressão mais impactante da violência homofóbica no contexto familiar; dando espaço a situações cotidianas, sistemáticas e sutis de humilhações e constante discriminação em que estes(as) jovens estão submetidos(as), ficando sob o mesmo teto que a família de origem. Situações corriqueiras de discriminação ancoradas em privilégios de seus parentes heterossexuais nas trocas familiares. Privilégios que sequer são reconhecidos, pelos(as) autores da violência e pelos(as) jovens em situação de violência familiar, como sendo privilégios. Tal resultado vai ao encontro de proposições encontradas na revisão da literatura internacional, que destacam a pluralidade 
de cenários e contextos da violência anti-homossexual e sua articulação com o machismo, como afirma Stephen Tomsen: "the growing research evidence about violence and abuse suggests more varied scenarios in patterns of victimization and the everyday masculinist concerns of perpetrators that coexist with bigotry and contempt for victims" (Tomsen, 2006, p. 402) ${ }^{1}$. Neste sentido, a pesquisa constatou que ainda que a violência homofóbica no âmbito familiar não culmine com a expulsão ou saída da casa dos pais, ela se processa nas relações cotidianas desses(as) jovens, quando permanecem no convívio de um lar heteronormativo, em que ser heterossexual lhes garantem posições privilegiadas ou, muitas vezes, posições de sobrevivência e não violência.

Outro ponto é que há situações que compõem contextos de vulnerabilidade específica de gênero, no que se refere à saúde das garotas e jovens lésbicas que precisam ser analisadas em maior profundidade, como por exemplo, os impactos da pressão normativa (em ter que manter relações sexuais com rapazes para fugir do desejo homoerótico na adolescência) nos corpos das garotas e jovens lésbicas, o que culmina muitas vezes em gravidez indesejada, infecção por DST e abortos, com sérios impactos na saúde das garotas e jovens lésbicas. As relações afetivas com pessoas do outro sexo, por sua vez, também aparecem como possibilidade de experimentação. Vale destacar que trabalhamos aqui com a perspectiva conceitual de experiência problematizada pela historiadora Joan Scott (1999), recusando a separação entre "experiência" e linguagem e insistir na qualidade produtiva do discurso. Nas palavras da autora:

A experiência, de acordo com essa definição, torna-se, não a origem de nossa explicação, não a evidência autorizada (porque vista ou sentida) que fundamenta o conhecimento, mas sim aquilo que buscamos explicar, aquilo sobre o qual se produz conhecimento. Pensar a experiência dessa forma é historicizá-la, assim como as identidades que ela produz (...) historicização que implica uma análise crítica de todas as categorias explicativas que normalmente não são questionadas, incluindo a categoria "experiência" (Scott, 1999, p. 27).

No que diz respeito aos impactos da violência homofóbica na saúde de jovens gays e lésbicas, foi possível constatar desdobramentos significativos na saúde mental que merecem ser pesquisados com maior atenção em pesquisas futuras. Um ponto a ser problematizado nesse aspecto referese à constatação de que alguns(mas) deles(as) não souberam fazer relações entre a violência sofrida, ainda que simbólica, e os possíveis impactos na saúde. Considerando que, quando as entrevistas foram realizadas, os conflitos já haviam acontecido, e os problemas de saúde, quando enunciados, aconteceram tempos depois. Por se tratar de violências cometidas por membros da família com quem mantinham relações de afeto, ficou evidente nas entrevistas certa dificuldade dos(as) informantes em reconhecer a violência, sobretudo, no momento em que ela ocorreu e, consequentemente, de perceber impactos em sua saúde. Apesar de todos(as) os/as participantes da pesquisa terem relatado sofrimento em relações de conflito familiar, de experienciarem quadros de tristeza e desânimo decorrentes da discriminação sofrida por familiares em relação a sua sexualidade, não identificaram estes aspectos como algo que diz respeito a sua saúde. É importante verificar como tanto a manutenção da estratégia de ocultação social de suas práticas e desejos, quanto o constante enfrentamento social pela estratégia de "sair do armário", podem ser associados não apenas aos impactos na saúde dos(as) jovens, mas também à reprodução da violência entre pares. O encobrimento de desejos e práticas privam jovens gays e lésbicas de suportes sociais importantes, como os de proteção e apoio por parte da família. Situações em que outros(as) jovens, heterossexuais, encontrariam redes de apoio e proteção social, sendo frequentemente protegidos por seus parentes mais velhos, são descritas como tendo um efeito contrário quando se trata de jovens gays e lésbicas.

Esses vetores levam a pensar como as estratégias de violência intrafamiliar não são consideradas como violência, implicando na minimização dos efeitos psicossociais da homofobia na saúde dos(as) entrevistados(as). Não tendo consciência do contexto de vulnerabilidade ao qual estão expostos(as), os/ as jovens não reconhecem de imediato a homofobia sofrida dentro dos próprios lares e quais os impactos desse processo na sua saúde. Se pensarmos este aspecto de legitimidade que essa forma de homofobia ganha, juntamente com as estratégias de enfrentamento que muitos(as) desses(as) jovens utilizam, percebe-se que muitos(as) apenas procuram amigos para relatar momentos de angústia, tristeza e culpa em decorrência de práticas desviantes da heteronormatividade, ou ainda a busca da fuga do contexto familiar, que se torna insuportável.

A guisa de conclusão, um elemento importante que merece ser destaque diz respeito ao controle da família sobre a sexualidade dos/as jovens. Tal controle toma proporções tamanhas que, em seus relatos, a maioria afirma que se sentia na obrigação de revelar a sua homossexualidade aos seus pais. Percebe-se o funcionamento de certo dispositivo confessional - tão bem problematizado por Michel Foucault em sua História da Sexualidade, em que o autor discorre acerca do processo oriundo do século XIX, no qual a sexualidade não fora reprimida, mas sim, incitada. Continua operando na contemporaneidade esse princípio confessional que leva o sujeito, a todo o momento, a confessar. Neste sentido, os relatos dos(as) informantes da pesquisa são frequentemente atravessados por esse princípio confessional, por meio do qual a família opera como dispositivo de regulação dos corpos, das condutas, dos desejos juvenis através da incessante (e muitas vezes, velada) "pressão para confessar". Neste sentido, vale lembrar, como bem afirmou Michel Foucault, que a confissão tornou-se uma poderosa técnica de produção da verdade. Seus efeitos apareceram na medicina, na psicologia, no direito, na pedagogia, nas relações familiares, nas relações amorosas, nas relações de amizade, nas diferentes esferas da vida. Procurase, no fundo de si mesmo, fazer falar uma verdade que a própria confissão acena como inacessível. Uma procura através das "palavras". É por estar a confissão tão amplamente difundida e tão profundamente incorporada ao cotidiano, que não a percebemos mais como efeito de um poder que nos coage (Foucault , 2006, p. 69).

Eis então uma compreensão importante acerca da "dinâmica do armário" no jogo de (in)visibilidade das práticas e 
identidades não heterossexuais no âmbito das famílias. Confessar, por vontade própria ou denúncia alheia, portanto, não se restringe ao domínio privado das relações familiares, atravessa a soleira da porta da casa para ser alvo do escrutínio público. A confissão se estende e é relançada a outros domínios da vida de jovens gays e lésbicas. Escolher um amigo ou uma amiga íntima para confessar suas angústias, seus temores, seus amores e prazeres passa a ser importante na vida de um/a adolescente gay ou lésbica. Muitos/as estabelecem, com seus pares, amizades íntimas e duradouras nas quais podem expressar suas narrativas autobiográficas e assim construírem estratégias de enfrentamento à violência que lhes é comum.

\section{Conclusões}

A pesquisa teve como objetivo investigar os aspectos psicossociais da ruptura do elo familiar por parte de jovens LGBT motivada pelo preconceito homofóbico e os efeitos disso na saúde destes/as jovens. A hipótese inicial central foi confirmada: a heteronormatividade legitima a produção e a manutenção de diversas situações de violência no seio da família, culminando muitas vezes com a expulsão/saída da casa de origem ou a submissão a sistemáticas violências familiares. Um aspecto importante do desenho de pesquisa que merece ser alvo de problematizações futuras e que se considera importante destacar no fechamento deste artigo, diz respeito a uma alteração metodológica exigida, no início da pesquisa, e que remete a uma reflexão. A amostra havia sido pensada, inicialmente, estabelecendo como critério de inclusão dos(as) informantes um corte etário de 15 a 30 anos, pois informações preliminares encontradas no campo (piloto) indicavam que muitos(as) jovens LGBT, menores de 18 anos, vivem em condições de maus tratos e humilhações perpetradas por parentes do núcleo familiar mais próximo. A inclusão destes(as) informantes era bastante relevante, tanto do ponto de vista metodológico quanto em seu potencial analítico em relação ao marcador social geracional. Entretanto, pela a Resolução 196/96 do Conselho Nacional de Pesquisa, que regulamenta os protocolos de ética em pesquisa com seres humanos, era exigido a assinatura do pai, da mãe ou de alguém responsável no Termo de Consentimento Livre e Esclarecido (TCLE) em caso de informantes menores de 18 anos. Entretanto, considerando o objetivo geral da pesquisa, como poderíamos solicitar as assinaturas dos(as) responsáveis sendo eles/elas, na maioria dos casos, ocupam a autoria da violência contra seus/suas jovens parentes gays/lésbicas? A solução adotada foi mudar o corte da amostra para jovens entre 18 e 30 anos. Vale indagar acerca dos aspectos éticos desta mudança. A ferida ética tão evitada pelos dispositivos burocráticos foi, aqui neste caso, exatamente, a privação do direito de jovens que possuem entre 15 a 18 anos de participarem de uma pesquisa que objetivou analisar uma problemática tão presente em suas vidas.

Para fins de fechamento das discussões propostas por este relato de pesquisa, destaca-se que, apesar do número de pesquisas sobre diferentes aspectos da homofobia ter crescido significativamente nos últimos dez anos, continua uma lacu- na na produção de estudos que analisem os aspectos psicossociais que envolvem, particularmente, as experiências de jovens lésbicas e gays em situações de violência e/ou abandono familiar. Também é importante retomar a proposição acerca de como é pouco expressiva as análises acerca do descompasso entre o marco legal sobre o direito de crianças e adolescentes e a atuação de diferentes atores sociais responsáveis por zelar pelo bem estar e desenvolvimento destas no que se refere à vivência da homossexualidade (Abramovay, Castro, \& Silva, 2004; Rios \& Nascimento, 2007; Souza, 2006; SPDCA/SEDH/ $P R$, 2004). Além disso, a invisibilidade e a ausência de políticas adequadas afetam também os profissionais e serviços de saúde que, na ausência de informações sobre essa população, agem a partir de estereótipos socialmente disseminados. Assim, a escassez de produção científica que aborde a temática da saúde de jovens LGBT no Brasil, somada à inexistência de políticas de saúde consistentes para o enfrentamento das dificuldades e das necessidades dessa população, acaba por reforçar o precário conhecimento sobre a especificidade de suas demandas e a ausência de adequadas tecnologias de cuidado à saúde.

\section{Referências}

Abramovay, M., Castro, M., \& Silva, L. (2004). Juventudes e sexualidade. Brasília: Unesco.

Allen, L., Glicken, A., Beach, R., \& Naylor, K. (1998). Adolescent health care experience of gay, lesbian, and bisexual young adults. Journal of Adolescent Health, 23(4), 212-220. doi: 10.1016/S1054-139X(98)00022-6

Blumenfeld, W. J. (1992). Squeezed into gender envelopes. In W. J. Blumenfeld (Org.), Homophobia: How we all pay the price (pp. 23-38). Boston: Beacon Press.

Borillo, D. (2001). Homofobia. Barcelona: Ediciones Bellaterra.

Butler, J. (2006). Deshacer el género. Barcelona: Paidós.

Carrara, S., Ramos, S., Simões, J. A., \& Facchini, R. (2006). Política, direitos, violência e homossexualidade. Pesquisa 9a Parada do Orgulho GLBT - São Paulo 2005. 1를. Rio de Janeiro: CEPESC.

Diniz, D., \& Guerriero, I. (2008). Ética na pesquisa social: Desafios ao modelo biomédico. Reciis, 2(1), 78-91. Recuperado de http://hdl.handle. net/10482/15251

Fonseca, C. (1999). Quando cada caso não é um caso: Pesquisa etnográfica e educação. Revista Brasileira de Educação,10, 58-78.

Foucault, M. (2004a). A Arqueologia do saber. Rio de Janeiro: Forense Universitária.

Foucault, M. (2004b). Polêmica, política, problematização. In M. Foucault (Org.), Ditos e Escritos - volume V (pp. 225-233). Rio de Janeiro: Forense Universitária.

Foucault, M. (2006). História da sexualidade I: A vontade de saber. Rio de Janeiro: Graal.

Kimmel, M. S., \& Mahler, M. (2003). Adolescent masculinity, homophobia, and violence: Random school shootings, 1982-2001. The American Behavioral Scientist, 46, 1439-1458.

Kosciw, J. G. (2004). The 2003 national school climate survey: The school-related experiences of our nation's lesbian, gay, bisexual, and transgender youth. Nova Iorque: GLSEN.

Lancaster, R. (1999). "That we should all turn queer?". Homosexual stigma in the making of manhood and the breaking of a revolution in Nicaragua. In R. Parker \& P. Aggleton (Orgs.), Culture, society and sexuality: A reader (pp. 104-122). Londres: UCL.

Lei n. ${ }^{\circ}$ 8.069, de 13 de julho de 1990. Dispõe sobre o Estatuto da Criança e 
do Adolescente e dá outras providências. Recuperado de http://www. planalto.gov.br/ccivil_03/leis/18069compilado.htm

Marre, J. (1991). História de vida e método biográfico. Cadernos de Sociologia, 3(3), 89-141.

Marsiaj, J. (2003). Gays ricos e bichas pobres: Desenvolvimento, desigualdade socioeconômica e homossexualidade no Brasil. Cadernos AEL, 10, 18-19.

Minayo, M. C. S. (1994). A Violência social sob a perspectiva da saúde pública. Cadernos de Saúde Pública, 10(1), 7-18. doi: 10.1590/S0102311X1994000500002

Osório, L. C. (1996). Família hoje. Porto Alegre: Artes Médicas.

Pellegrini, A. (1992). S(h)ifting the terms of hetero/sexism: Gender, power, homophobias. In W. J. Blumenfeld (Org.), Homophobia: How we all pay the price (pp. 39-56). Boston: Beacon Press.

Pereira, H., \& Leal, I. P. (2005). Medindo a homofobia internalizada: A validação de um instrumento. Análise Psicológica, 3(23), 323-328. Recuperado de http://hdl.handle.net/10400.12/191

Phoenix, A., Frosh, S., \& Pattman, R. (2003). Producing contradictory masculine subject positions: Narratives of threat, homophobia, and bullying in 11-14 year old boys. Journal of Social Issues, 59, 179-195. doi: 10.1111/1540-4560.t01-1-00011

Pilkington, N. W., \& D’Augelli, A. R. (1995). Victimization of lesbian, gay, and bisexual youth in community settings. Journal of Community Psychology, 23(1), 34-56. doi: 10.1002/1520-6629(199501)23:1<34::AIDJCOP2290230105>3.0.CO;2-N

Plummer, D. C. (2001). The quest for modern manhood: Masculine stereotypes, peer culture and the social significance of homophobia. Journal of Adolescence, 24(1), 15-23. doi: 10.1006/jado.2000.0370

Poteat, V. P., \& Espelage D. L. (2007). Predicting psychosocial consequences of homophobic victimization in middle school students. Journal of Early Adolescence, 27(2), 175-91. doi:10.1177/0272431606294839

Prado, M. A., \& Machado, F. V. (2008). Preconceito contra homossexualidades: A hierarquia dainvisibilidade. São Paulo: Cortez Editora.

Preciado, B. (2011). Manifesto contrasexual. Barcelona: Anagrama.

Rabinow, P. (1999). Antropologia da razão. Rio de Janeiro: Relume-Dumará.

Remafedi G. (1987). Adolescent homosexuality: Psychosocial and medical implications. Pediatrics, 79,331-337.

Rios, L. F., \& Nascimento, I. F. (2007). Homossexualidade e psicoterapia infantil - possibilidades e desafios para a construção dos direitos sexuais na clínica psicológica. Revista de Psicologia Política, 7(13), 61-96. Recuperado de http://www.fafich.ufmg.br/ psicopol/seer/ojs/viewarticle.php?id=36

Rivers, I. (2001). The bullying of sexual minorities at school: Its nature and long-term correlates. Educational and Child Psychology, 18(1), 32-46.

Rubin, G. (1984). Thinking sex: Notes for a radical theory of the politics of sexuality. In C. S.Vance (Org.) Pleasure and danger: Exploring female sexuality (267-319). London: Routledge.

Saggese, G. S. R. (2009). Quando o armário é aberto: Visibilidade e estratégias de manipulação no coming out de homens homossexuais (Dissertação de mestrado não publicada). Universidade do Estado do Rio de Janeiro, Instituto de Medicina Social.

Sahlins, M. (1990). Ilhas de história. Rio de Janeiro: Zahar.

Scott, J. (1999) Experiência. In A. L. Silva, M. C. S. Lago \& T. R. O. Ramos (Orgs.), Falas de gênero (pp. 21-55). Florianópolis: Editora Mulheres.

Sedgwick, E. K. (2007). A epistemologia do armário. Cadernos Pagu, 28, 19-54.

Sluzki, C. E. (1997). A rede social na prática sistêmica: Alternativas terapêuticas. São Paulo: Casa do Psicólogo.

Soliva, T. B. (2009). Quando a casa é o lugar do perigo: um estudo da violência intrafamiliar sofrida por jovens homossexuais. In VIII Reunión de Antropología del Mercosur (RAM), 2009, Buenos Aires. Anais da VIII Reunión de Antropología del Mercosur (RAM): Diversidad y poder en América Latina.
Souza, E. (2006). Marcadores sociais da diferença e infância: Relações de poder no contexto escolar. Cadernos Pagu, 26, 169-199. doi: 10.1590/S010483332006000100008

SPDCA/SEDH/PR (2004). Relatório da oficina de trabalho - Criança e adolescência: sexualidade $x$ violação de direitos. Mimeo, Brasília.

Toledo, L. G., \& Teixeira Filho, F. S. (2013) Homofobia familiar: Abrindo o armário 'entre quatro paredes'. Arquivos Brasileiros de Psicologia, 65(3), 376-391.

Tomsen, S. (2001). 'Hate crimes and masculine offending'. Gay and Lesbian Law Journal, 10, 1-17.

Tomsen, S. (2002). Hatred, murder and male honour: Anti-homosexualhomicides in New South Wales, 1980-2000. Canberra: Australian Institute of Criminology.

Tomsen, S. (2006). Homophobic violence, cultural essentialism and shifting sexual identities. Social \& Legal Studies, 15(3), 389-407. doi: 10.1177/0964663906066616

Warner, M. (1993). Fear of a queer planet. Minneapolis: University of Minnesota. 


\section{Nota}

1. "A crescente evidência de pesquisa sobre violência e abuso sugere cenários mais variados no padrão de vitimização e as preocupações machistas cotidianas dos autores que coexistem com a intolerância e o desprezo para com as vítimas" (Tomsen, 2006, p. 402).

Juliana Perucchi, Doutora pelo Programa de Pós-graduação em Psicologia da Universidade Federal de Santa Catarina (UFSC), é professora Adjunta III do Departamento de Psicologia e professora-pesquisadora do Programa de Pós-graduação em Psicologia da Universidade Federal de Juiz de Fora (UFJF). Endereço para correspondência: Rua Antônio José Martins, 140 ap. 409. Morro do Glória, CEP 36036-050. Juiz de Fora - MG. E-mail: jperucchi@gmail.com

Brune Coelho Brandão, psicóloga formada pela Universidade Federal de Juiz de Fora (UFJF), é mestranda pelo Programa de Pós-graduação em Psicologia da Universidade Federal de Juiz de Fora (UFJF). E-mail: brunecbrandao@yahoo.com.br

Hortênsia Isabela dos Santos Vieira, psicóloga formada pela Universidade Federal de Juiz de Fora (UFJF), é mestranda pelo Programa de Pós-graduação em Psicologia da Universidade Federal de Juiz de Fora (UFJF). E-mail: hortensia.vieira@yahoo.com.br 